\title{
Plant architecture and vegetation structure: Two ways for insect herbivores to escape parasitism
}

\author{
Elisabeth OBERMAIER ${ }^{1 *}$, ANNetTe HEISSWOLF ${ }^{2,5}$, HANS Joachim POETHKE ${ }^{2}$, BarbaRa RANDLKOFER ${ }^{3}$ \\ and TORSTEN MEINERS ${ }^{3}$ \\ ${ }^{1}$ Department of Animal Ecology and Tropical Biology, University of Würzburg, Biozentrum, Am Hubland, D-97074 Würzburg, \\ Germany; e-mail: o.maier@biozentrum.uni-wuerzburg.de \\ ${ }^{2}$ Field Station Fabrikschleichach, University of Würzburg, Germany \\ ${ }^{3}$ Department of Applied Zoology/Animal Ecology, Free University of Berlin, Germany
}

Key words. Chrysomelidae, enemy free space, Galeruca tanaceti, environmental heterogeneity, oviposition site, parasitism, plant architecture, Oomyzus galerucivorus, structural complexity, vegetation structure

\begin{abstract}
Interactions between herbivorous insects and their parasitoids occur in highly structured and complex environments. Habitat structure can be an important factor affecting ecological interactions between different trophic levels. In this study the influence of plant architecture and surrounding vegetation structure on the interaction between the tansy leaf beetle, Galeruca tanaceti L. (Coleoptera: Chrysomelidae) and its egg parasitoid, Oomyzus galerucivorus Hedqvist (Hymenoptera: Eulophidae), was investigated at two small spatial scales in the field. It was expected that high and structurally complex plants or vegetation represent an enemy free space for the herbivore by making host search more difficult for the parasitoid. At the scale of individual plants, plant height had a positive influence on herbivore oviposition and egg clutch height a negative impact on parasitism. In addition, the beetle was more likely to oviposit on simple plants than on plants with branches, while the parasitoid remained unaffected by the degree of branching. At the microhabitat scale ( $\mathrm{r}=0.1 \mathrm{~m}$ around an oviposition site), both height and density of the vegetation affected beetle oviposition positively and egg parasitism negatively. The herbivore and its parasitoid, therefore, were influenced in opposite ways by habitat structure at both spatial scales investigated, suggesting the existence of an enemy free space for the herbivores' eggs on tall plants and in tall and complex vegetation. This study indicates that structural components of the environment are important for interactions among organisms of different trophic levels.
\end{abstract}

\section{INTRODUCTION}

Host-parasitoid interactions do not take place in homogeneous but in highly structured and complex environments (Casas \& Djemai, 2002). The structure of individual plants and the vegetation structure of habitat patches in general can influence the movement of herbivores (Crist et al., 1992), their decision to enter a habitat (Cronin, 2003), duration of stay (Bach, 1984), abundance (Anthes et al., 2003; Dennis, 2004; Raghu et al., 2004), and mortality (Kaitaniemi et al., 2004). Structure can, however, also indirectly influence herbivorous insects via their natural enemies. At the scale of individual plants, Andow \& Prokrym (1990) and Lukianchuk \& Smith (1997) showed that a complex plant architecture not only reduces the probability of an egg parasitoid finding its hosts eggs, but also functionally reduces the parasitoids' searching time depending on the complexity of the plant. Gingras et al. (2002) drew the same conclusions from a model of the influence of plant architecture on parasitism rate, which was validated in three natural tritrophic systems. Also at larger spatial scales vegetation structure influences the probability that hosts and patches with hosts are found by parasitoids (Kemp \& Simmons, 1978; Price et al., 1980; Finke \& Denno, 2002) as well as the abundance of their natural enemies (Langellotto \&
Denno, 2004). The importance of structural complexity for host-parasitoid interactions, however, has only recently started to be investigated (Casas \& Djemai, 2002; Cronin, 2003; Meiners \& Obermaier, 2004; Tschanz et al., 2005, Riihimäki et al., 2006).

Potential hosts of parasitoids can avoid parasitism by preferring oviposition sites where parasitoids are rare or absent (Quicke, 1997). The use of "enemy free space" was defined by Jeffries \& Lawton (1984) as the "way of living that reduces or eliminates a species" vulnerability to one or more species of natural enemies' and is known to exist in several systems (Berdegué et al., 1996; Hopkins \& Dixon, 1997; Gratton \& Welter, 1999; Heisswolf et al., 2005). Regarding habitat structure, herbivores may make use of enemy free space by ovipositing on architecturally complex plants or within structurally complex vegetation where the risk of parasitism may be lower.

The polyphagous tansy leaf beetle, Galeruca tanaceti L. (Coleoptera: Chrysomelidae), deposits its egg clutches in late autumn mainly on dry stalks of non-host plants within semi-dry grassland sites where the egg clutches then hibernate. There, the eggs are exposed to Oomyzus galerucivorus Hedqvist (Hymenoptera: Eulophidae), the only egg parasitoid of $G$. tanaceti in the study area. It was expected that a high and complex plant architecture and

\footnotetext{
* Present address: Section of Ecology, Department of Biology, University of Turku, Finland.
} 
TABLE 1. Overview of the structural parameters at the two spatial scales studied in terms of their effect on egg distribution of $G$. tanaceti and parasitism by $O$. galerucivorus. Structural parameters were categorized according to the height of the respective structure and the structural complexity of the plant or habitat patch (after Gingras et al., 2002, modified for the different scales). Parameters, which are correlated significantly within a scale, are indicated by an asterisk $\left(^{*}\right)$ and are combined by principal component analysis to the factor vegetation structure.

\begin{tabular}{|c|c|}
\hline \multicolumn{2}{|c|}{ Structural parameters studied } \\
\hline Height & Complexity \\
\hline $\begin{array}{l}\text { Individual plant scale } \\
\text { - } \quad \text { Plant height } \\
\text { - } \quad \text { Egg clutch height }\end{array}$ & $\begin{array}{ll}\text { - } & \text { Number of ramifications } \\
\text { - } & \text { Patterns of ramifications (simple / ramified) }\end{array}$ \\
\hline $\begin{array}{l}\text { Microhabitat scale }(\mathrm{r}=0.1 \mathrm{~m}) \\
\text { - } \quad \text { Height of herbaceous layer * } \\
\quad(\text { mean/maximum vegetation height })\end{array}$ & $\begin{array}{l}\text { - } \% \text { Vertical cover of herbs, grasses and open ground } \\
\text { - } \% \text { Horizontal vegetation cover * } \\
\text { - } \quad \text { Number of stalks * }\end{array}$ \\
\hline
\end{tabular}

vegetation structure may both impede host finding by the parasitoid and provide enemy-free space for the egg clutches of the herbivore. Plant architecture was previously defined by the size, heterogeneity and structural complexity of the plant (plant form) (Andow \& Prokrym, 1990; Gingras et al., 2002). In this study, this definition was extended to larger spatial scales and plant architecture and vegetation structure were categorized by their height (height of the structure) or structural complexity (number of ramifications, vegetation cover or stalk number; Table 1).

In order to more completely understand the role of structure for host-parasitoid interactions, we asked whether (1) the probability of herbivore oviposition increases and (2) the probability of parasitism decreases with increasing height and structural complexity at the respective spatial scale.

\section{MATERIAL AND METHODS}

\section{Study system}

This study was conducted on low-intensity managed meadows and semi-dry grassland sites within the "Hohe Wann" nature reserve (Northern Bavaria, Germany, $50^{\circ} 03^{\prime} \mathrm{N}, 10^{\circ} 35^{\prime} \mathrm{E}$ ). The size of the nature reserve is approximately 1000 ha.

The tansy leaf beetle, Galeruca tanaceti, is polyphagous and feeds on species of the families Asteraceae, Brassicaceae, Caryophyllaceae, Dipsacaceae, Liliaceae, Lamiaceae, Polygonaceae and Solanaceae (Lühmann, 1939; Prevett, 1953; Obermaier \& Zwölfer, 1999). In the study area, one of the main host plants of G. tanaceti is yarrow, Achillea millefolium L. (Asterales: Asteraceae), (Meiners \& Obermaier, 2004), but larvae can also be found feeding on Centaurea jacea L. (Asterales: Asteraceae) and Salvia pratensis L. (Lamiales: Lamiaceae).

In autumn, females of the tansy leaf beetle deposit their egg clutches on vertical structures within the herbaceous vegetation layer, mostly on grass and other non-host plants (E. Obermaier, pers. observ.), where the egg clutches then hibernate (Meiners et al., 2006). The gravid females are unable to fly and have to walk up the plant structures to oviposit. About one egg clutch is deposited per week so beetles may disperse considerable distances between suitable oviposition sites within heterogeneous environments. After hatching in April-May, the larvae seek suitable host plants close to the oviposition site, on which they feed for about three weeks until pupation (Obermaier \& Zwölfer, 1999). After pupation, the adults can be found from early June onwards before they enter reproductive diapause in mid-summer.

The eulophid wasp O. galerucivorus parasitizes different Galeruca species (Sinacori \& Mineo, 1993), however, its main host in Germany is the tansy leaf beetle. O. galerucivorus parasitizes the egg clutches of its host shortly after beetle oviposition in autumn. The parasitoid larvae hibernate in the host eggs and adults emerge next spring (Meiners et al., 2006). The $1.5 \mathrm{~mm}$ long egg parasitoids search for host egg clutches by walking up and down vertical structures within the vegetation and using chemical contact cues associated with the host's faeces (Meiners et al., 1997 and unpubl. data).

\section{Sampling design}

Plant architecture and vegetation structure were examined at two grassland sites called "site 1" and "site 2" and in two different years. The two sites were similar in that there were sufficiently high densities of ovipositing females, a moderate density of the main host plant, A. millefolium, comparable slopes, the same biotope type (semi-dry grassland), approximately the same altitude ("site 1" $280 \mathrm{~m}$, "site 2" $300 \mathrm{~m}$ above NN) and they were only $1900 \mathrm{~m}$ apart. For each site and year a certain number of random points was selected on aerial photographs of the sites using the Geographical Information Software Arc View GIS 3.2 (ESRI, Redlands, California). In the field, the random points were located using a portable GPS. At about half of the random points the point was shifted to the nearest plant with an egg clutch of $G$. tanaceti, and this plant and egg clutch were selected for investigation. The remaining random points per site were used as controls without egg clutches. The sampling design and sample sizes are presented in Table 2.

As after the first year the data on the effect of plant architecture were still incomplete this part of the study was repeated in the second year. Therefore the data set for the first year was used for a comparison of the effect of vegetation structure on the herbivore and parasitoid, and a combined analysis of plant architecture and vegetation structure on parasitism; the data set for the second year, in contrast, was used to compare the effect of plant architecture on the herbivore and parasitoid.

\section{Parameters investigated at the individual plant scale}

For all selected plants with egg clutches and random plants at control points egg clutch height (if available), plant height, pattern (simple/ramified) and number of ramifications were recorded. Egg clutches were collected for analysis of parasitism.

\section{Parameters investigated at the microhabitat scale $(r=0.1 \mathrm{~m})$}

Around both, the egg clutch points and control points different measures of vegetation structure were recorded within a circle of $0.1 \mathrm{~m}$ radius. The average height (i.e. the weighted 
TABLE 2. Method of sampling the structural parameters describing plant architecture and vegetation structure at sites 1 and 2 in year 1 and 2. At each site parameters were measured at random points without egg clutches and random points with egg clutches as indicated. " $n$ " indicates the sample size and when and where data were collected in the field.

\begin{tabular}{llccccc}
\hline \multirow{2}{*}{ Scale/Year } & & \multicolumn{2}{c}{ Plant architecture } & & \multicolumn{2}{c}{ Vegetation structure } \\
\cline { 3 - 4 } \cline { 5 - 6 } & & Site 1 & Site 2 & & Site 1 & Site 2 \\
\hline \multirow{2}{*}{ Year 1 } & Random points without egg clutches & - & - & & $\mathrm{n}=20$ & $\mathrm{n}=20$ \\
& Egg clutch points & $\mathrm{n}=60$ & $\mathrm{n}=20$ & & $\mathrm{n}=60$ & $\mathrm{n}=20$ \\
\multirow{2}{*}{ Year 2 } & Random points without egg clutches & $\mathrm{n}=50$ & - & - & - & - \\
& Egg clutch points & $\mathrm{n}=50$ & - & & - & - \\
\hline
\end{tabular}

mean vegetation height of Sundermeier, 1999) and the maximum height of the herbaceous layer were measured. The number of plant stalks was counted and the vertical cover of herbs, grasses, and open ground was estimated. The horizontal vegetation cover was estimated in $0.1 \mathrm{~m}$ steps from $0 \mathrm{~m}$ up to $1.0 \mathrm{~m}$ using a white wooden board as background (Sundermeier, 1999). Additionally, the occurrence of A. millefolium, the main host plant of $G$. tanaceti, was recorded.

As the parasitoids may not only be influenced by vegetation structure but also by the density of host egg clutches, egg clutch abundance of $G$. tanaceti was further determined at three radii, 1 $\mathrm{m}, 1.5 \mathrm{~m}$ and $2 \mathrm{~m}$, around the random sample points with egg clutches.

\section{Analysis of parasitism}

Finally, the selected egg clutches from the egg clutch points studied were collected from the two sites at the end of October and kept outdoors in the shade until the end of November. Then they were put singly in vials that were sealed with a fine net and kept for several weeks at room temperature until beetle larvae and adult parasitoids had hatched. The net was sprayed with water every three days to prevent egg clutches from drying out.

Parasitism was registered as incidence, i.e. whether at least one parasitoid hatched from the egg clutch. To estimate the rate of parasitism per clutch, egg clutches from site $1(n=60)$ were dissected after parasitoids had hatched. Rate of parasitism was calculated as number of parasitoids that hatched or stayed within the eggs completely developed divided by the total number of eggs per egg clutch.

\section{Statistics}

The influence of structural parameters was analyzed using multiple logistic regressions (Jongman et al., 1995; Hosmer \& Lemeshow, 2000) or multiple linear regressions (Sokal \& Rohlf, 1995). Prior to analysis, collinearity of habitat variables was eliminated by principal components analysis. The factor "vegetation structure" consisted of the parameters maximum and mean vegetation height, number of stalks, and horizontal vegetation cover at $0.3 \mathrm{~m}$ height, the factor "vegetation architecture" of all parameters included in "vegetation structure" and additionally egg clutch height. All parameters combined by principal components analysis were significantly positively correlated with each other.

To evaluate the goodness-of-fit of the logistic regression models the coefficient of determination $R^{2}$ of Nagelkerke (1991) were calculated. $R O C$ (receiver operating characteristic) plots, i.e. the area under the resulting plot (area under curve $=A U C$ ), were used to determine the classification accuracy of the model (Zweig \& Campbell, 1993; Guisan \& Zimmermann, 2000; Bonn $\&$ Schröder, 2001). $A U C$ values vary from 0.5 (determination by chance) to 1.0 (perfect classification). For model validation at the scale of the microhabitat, models were calculated for each site separately and then externally validated with the data from the other site (Fleishman et al., 2003; Schröder \& Reineking,
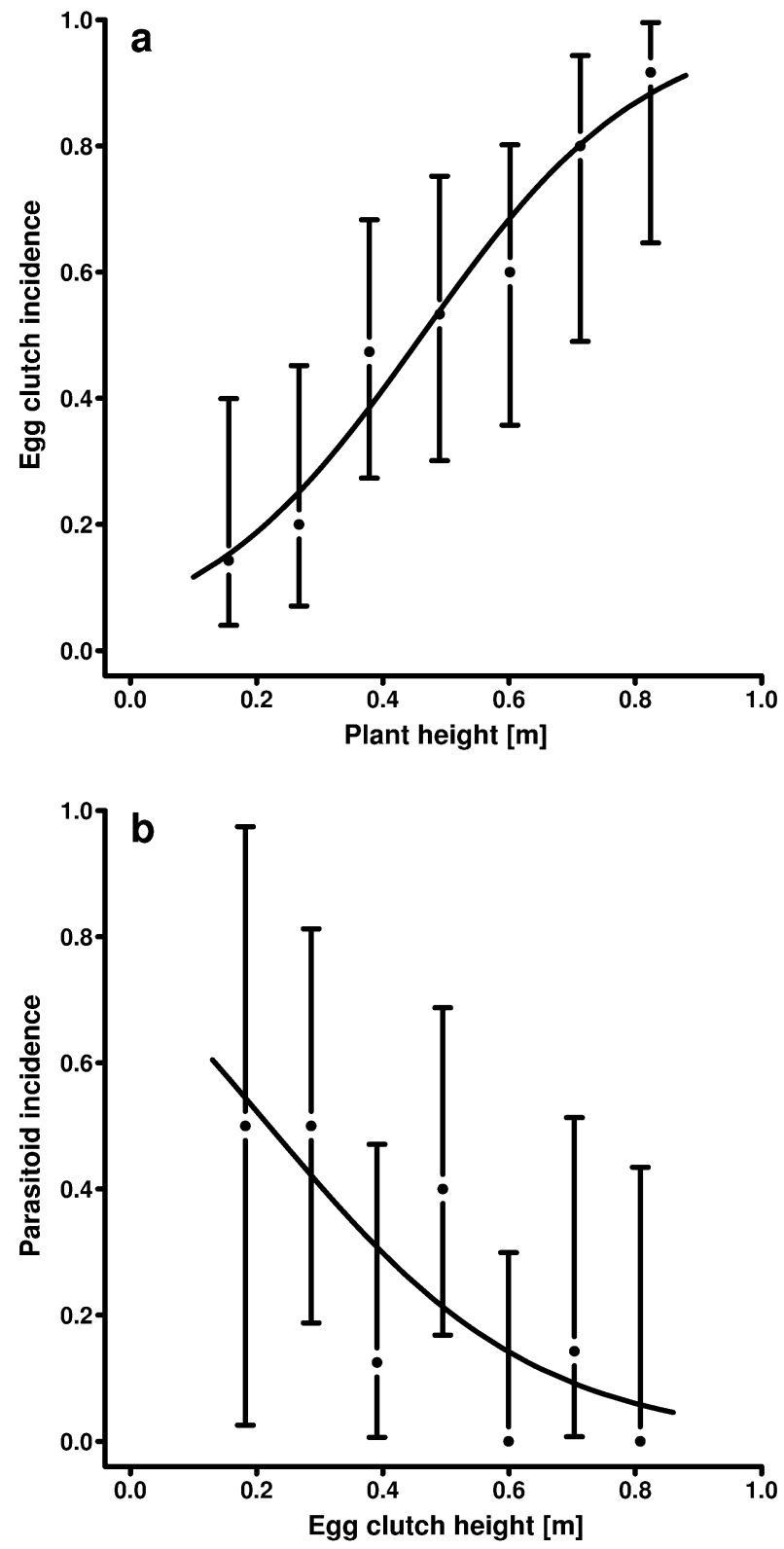

Fig. 1. Oviposition of G. tanaceti (a) and parasitism by $O$. galerucivorus (b) at different plant (a) and egg clutch (b) heights. Plotted are the mean $\pm 95 \%$ CI of egg clutch or parasitoid incidences (circles with bars) and the predicted probability of egg clutch or parasitoid incidence (line) calculated by the logistic regression models. $n=100$ plants (a), $n=60$ plants with egg clutches (b). 

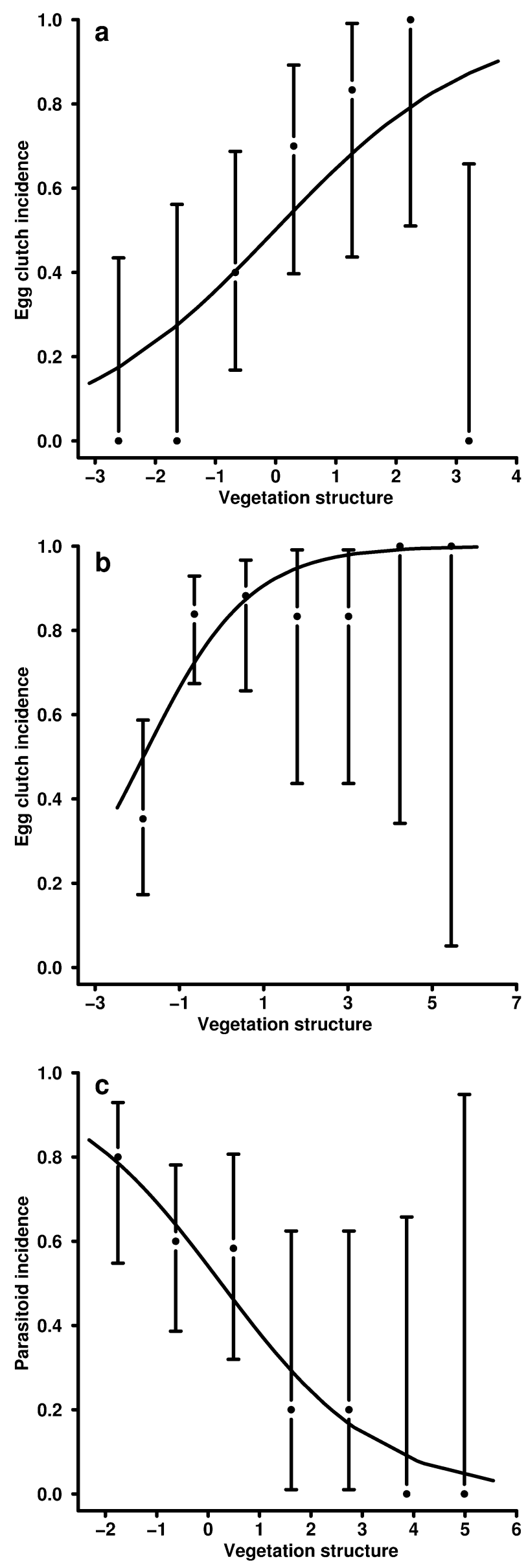

2004). The success of the validation was measured using again the $A U C$ value (Bonn \& Schröder, 2001; Manel et al., 2001).

Multiple linear regressions were used to analyze the effect of structural parameters on rate of parasitism. Residuals were tested for normal distribution and all variables consisting of percentage values were arcsin-transformed (Sokal \& Rohlf, 1995). As above, collinearity of variables was avoided by principal components analysis. All procedures were calculated with the software package SPSS 14.0 (SPSS Inc., 2006).

\section{RESULTS}

\section{Plant architecture: Herbivore oviposition}

Plant architecture was characterized by plant height and plant structural complexity (Table 1). Oviposition probability significantly increased with increasing plant height (coefficient $=5.593, p=0.001$, Fig. 1a), and was higher on simple plant stems than on plant stems with ramifications (coefficient $=0.973, \mathrm{p}=0.094)\left(R_{\text {Nagelkerke }}^{2}=0.334, P\right.$ $=0.001, A U C=0.799, P_{A U C}=0.001, n=100$, year 2$)$. The second variable improved the fit of the overall model and was therefore included. The variable "number of ramifications", in contrast, was excluded by the analysis. Therefore, beetle females used mainly high plants for oviposition, and in addition showed a slight preference for plants with low plant structural complexity.

\section{Plant architecture: Parasitism}

The height at which an egg clutch was deposited had a significantly negative impact on its probability of being parasitized by $O$. galerucivorus in both years of the investigation (coefficient $=-0.027, R_{\text {Nagelkerke }}^{2}=0.095, P=$ $0.047, A U C=0.637, P_{A U C}=0.07, n=60$, year 1$)$, (coefficient $=-4.742, R^{2}{ }_{\text {Nagelkerke }}=0.160, P=0.024, A U C=$ $0.731, P_{A U C}=0.026, n=47$, year 2) (Fig. 1b). Egg clutch height was significantly positively correlated with plant height $\left(r_{P}=0.97, P=0.001, n=50\right)$. In contrast, both measures of structural complexity, i.e. the pattern and number of ramifications per plant, were removed by the multiple logistic regression model and had no significant influence on parasitism. Therefore, only egg clutch height influenced parasitism at the scale of individual plants.

\section{Vegetation structure in the microhabitat $(r=0.1 \mathrm{~m})$ : Herbivore oviposition}

At both study sites, the probability of oviposition by $G$. tanaceti significantly increased with increasing height and density of the vegetation structure around the oviposition site ( site 2: coefficient $=0.992, R_{\text {Nagelkerke }}^{2}=0.225, P$ $=0.007, A U C=0.775, P_{A U C}=0.001, n=40$, year 1) (Fig. $2 \mathrm{a})$; $\left(\right.$ site 1 : coefficient $=1.360, R^{2}{ }_{\text {Nagelkerke }}=0.215, P=$

Fig. 2. Oviposition of G. tanaceti $(\mathrm{a}+\mathrm{b})$ and parasitism by $O$. galerucivorus (c) in different vegetation structures $[=$ factor composed of vegetation height ( $\max$, mean), $\%$ horizontal vegetation cover at a height of $0.3 \mathrm{~m}$, and stalk number] at the microhabitat scale $(\mathrm{r}=0.1 \mathrm{~m})$. Plotted are the mean $\pm 95 \% \mathrm{CI}$ of egg clutch or parasitoid incidences (circles with bars) and the predicted probability of egg clutch or parasitoid incidence (line) calculated by the logistic regression models at "site 2 ", $n=40$ microhabitats (a), "site 1", $n=80$ microhabitats (b) and "site 1", $n=60$ microhabitats (c). 
TABLE 3. Cross-validation of the logistic regression model of the egg distribution of $G$. tanaceti depending on microhabitat vegetation structure at the two sites. Models were parameterized with data from one site (training site, left column) and validated using the data from the other site (test site, first row). Given are $A U C( \pm S E)$ and $p$-values of the validations. $n=80$ microhabitats (site 1) and $n=60$ microhabitats (site 2).

\begin{tabular}{lccc}
\hline Training $\backslash$ Test & & Site 1 & Site 2 \\
\hline \multirow{3}{*}{ Site 1 } & $A U C$ & 0.768 & 0.785 \\
& $S E$ & 0.069 & 0.081 \\
& $P$ & 0.001 & 0.01 \\
\multirow{3}{*}{ Site 2 } & $A U C$ & 0.764 & 0.775 \\
& $S E$ & 0.069 & 0.081 \\
& $P$ & 0.001 & 0.01 \\
\hline
\end{tabular}

$0.001, A U C=0.768, P_{A U C}=0.001, n=80$, year 1) (Fig. $2 b)$. The factor "vegetation structure" consisted of the parameters maximum and mean vegetation height, number of stalks, and horizontal vegetation cover at $0.3 \mathrm{~m}$ height, i.e. beetle eggs were found most often in tall and dense vegetation. As the model was successfully crossvalidated at both sites (Table 3), it seems to be a general phenomenon.

The probability that a $G$. tanaceti egg clutch was present was not correlated with the presence of the main host plant $A$. millefolium (yarrow) at the microhabitat scale. At site 1, yarrow was present in $91 \%$ of the investigated microhabitats, at site 2 in $50 \%$.

\section{Vegetation structure in the microhabitat $(r=0.1 \mathrm{~m})$ : Parasitism}

Parasitism could be investigated only at site 1 since none of the egg clutches collected at the second site are parasitized. There was a highly significantly negative correlation between the probability of parasitism and the factor "vegetation structure" around the oviposition site (coefficient $_{\mathrm{veg}}=-1.154, \mathrm{p}_{\mathrm{veg}}=0.004, R^{2}{ }_{\text {Nagelkerke }}=0.352, P$ $=0.001, A U C=0.79, P_{A U C}=0.001, n=60$, year 1) (Fig. $2 c)$. The factor "vegetation structure" consisted of the same parameters as above. At the same time the probability of parasitism increased with increasing density of $G$. tanaceti egg clutches within a radius of $2 \mathrm{~m}$ around the oviposition site $\left(\right.$ coefficient $\left._{\text {density }}=0.448, p_{\text {density }}=0.029\right)$. The rate of parasitism of $G$. tanaceti egg clutches was also significantly negatively correlated with vegetation structure (coefficient $=-0.162, R_{\text {adjusted }}^{2}=0.110, P=$ $0.006, n=60$, year 1 ) and showed a tendency to be positively correlated with host density (coefficient $=0.064$, $R_{\text {adjusted }}^{2}=0.05, P=0.051, n=60$, year 1$)$.

\section{Combined analysis of plant architecture and vegetation structure: Parasitism}

Investigating the influence of different measures of plant architecture (height, pattern (simple / ramified) and number of ramifications) and the factor "vegetation structure" on the probability of parasitism, only the factor "vegetation structure" attributed significantly to the logistic regression model (coefficient $=-1.108, R^{2}$ Nagelkerke $=0.249, P=0.001, A U C=0.725, P_{A U C}=0.003, n=60$,

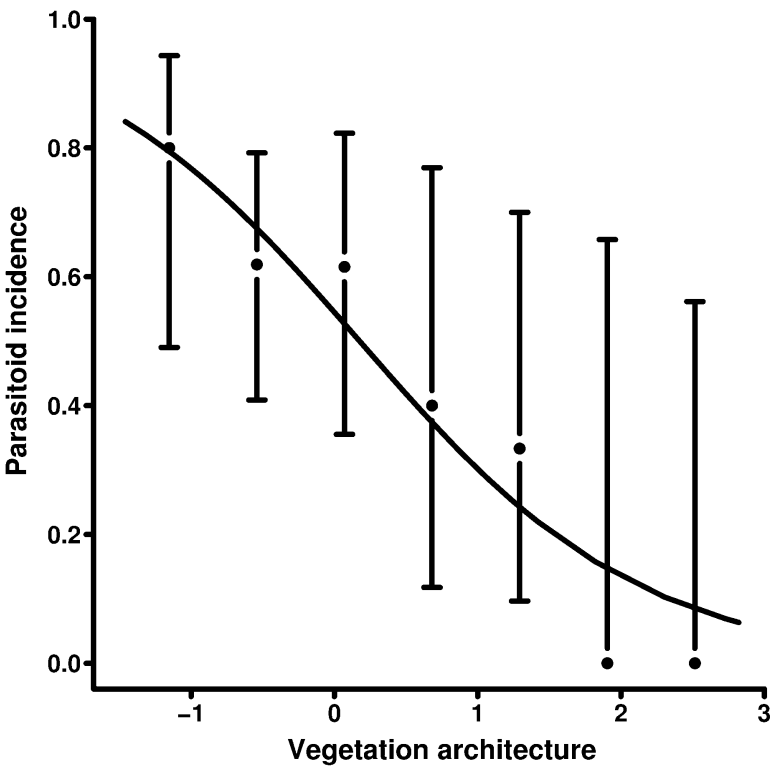

Fig. 3. Parasitism by $O$. galerucivorus in different vegetation architecture (= factor composed of egg clutch height, vegetation height (max, mean), \% horizontal vegetation cover at a height of $0.3 \mathrm{~m}$, and stalk number). Plotted are the mean $\pm 95 \%$ CI of parasitoid incidences (circles with bars) and the predicted probability of parasitoid incidence (line) calculated by the logistic regression models. $n=60$ microhabitats.

year 1). Since egg clutch height and the factor "vegetation structure" were significantly positively correlated $\left(r_{P}=\right.$ $0.604, P=0.001$ ) both were combined in a new factor "vegetation architecture", which is also significantly negatively correlated with the probability of parasitism (coefficient $=-1.018, R_{\text {Nagelkerke }}^{2}=0.231, P=0.001, A U C=$ $0.730, P_{A U C}=0.002, n=60$, year 1) (Fig. 3) and rate of parasitism (coefficient $=-0.163, R_{\text {adjusted }}^{2}=0.112, P=$ $0.006, n=60$, year 1$)$.

\section{DISCUSSION}

As insect herbivores depend primarily on their host plants for survival and reproduction, analyses of the abundances and distribution patterns of these plants have been the basis of many studies on herbivore-plant interactions (Bernays \& Chapman, 1994). Recently it was emphasized, however, that this approach may be too restricted and the habitats for insect herbivores defined too narrowly. In particular, non-consumable resources (structural elements) are ignored (Dennis, 2004). The present study is one of the first to examine effects of plant and vegetation structure per se, apart from the effects of host plant availability, usually correlated with (host) plant size and density, in the field. This was possible since the model organisms studied almost exclusively use dry structures of non-host plants for oviposition. The study reveals that plant architecture and vegetation structure do not only influence distributions of herbivores or parasitoids, but even seem to have the potential to mediate interactions across different trophic levels (host-parasitoid interactions). Table 4 gives a schematic overview of the 
TABLE 4. Overview of the influence of plant architecture and vegetation structure on herbivore oviposition and parasitism of egg clutches of Galeruca tanaceti at two spatial scales. + denotes a significantly positive relationship, - a significantly negative relationship, n.s. means not significant. * indicates variables summarized by PCA to the factor "vegetation structure".

\begin{tabular}{|c|c|c|c|}
\hline Scale & Variable & Herbivore oviposition & Parasitism \\
\hline \multirow{4}{*}{ Individual plant } & Plant height & + & \\
\hline & Egg clutch height & & - \\
\hline & Number of ramifications & n.s. & n.s. \\
\hline & Patterns of ramification (simple / ramified) & + & n.s. \\
\hline \multirow{13}{*}{ Microhabitat } & Maximum vegetation height $*$ & + & - \\
\hline & Weighted mean vegetation height $*$ & + & - \\
\hline & Number of stalks * & + & - \\
\hline & Vertical cover of herbaceous plants, grass, open ground & n.s. & n.s. \\
\hline & Horizontal vegetation cover & & \\
\hline & - $\quad 0.10 \mathrm{~m}$ & n.s. & - \\
\hline & - $\quad 0.20 \mathrm{~m}$ & n.s. & - \\
\hline & - $\quad 0.30 \mathrm{~m} *$ & + & - \\
\hline & - $\quad 0.40 \mathrm{~m}$ & + & n.s. \\
\hline & - $\quad 0.50 \mathrm{~m}$ & + & n.s. \\
\hline & Factor "vegetation structure" (PCA including all *) & + & - \\
\hline & Host plant incidence & n.s. & n.s. \\
\hline & Egg clutch density & & + \\
\hline
\end{tabular}

influences of plant and vegetation structure on the herbivore-parasitoid system studied at two spatial scales.

At the scale of an individual plant, plant architecture is defined in terms of the size and structural complexity of a plant (Table 1; after Andow \& Prokrym, 1990 and Gingras et al., 2002). In the literature, structural complexity is recorded as affecting herbivores (Raghu et al., 2004; Rudgers \& Whitney, 2006) and parasitoids (Andow \& Prokrym, 1990; Lukianchuk \& Smith, 1997). In several studies, host finding success of parasitoids is higher on simple structured plants than on those with complex structures (Andow \& Prokrym, 1990; Lukianchuk \& Smith, 1997; Gingras et al., 2002, 2003). Likewise, on large plants or in complex canopies herbivores are better able to escape predation, at least by some species of natural enemies (Heisswolf et al., 2005; Riihimäki et al., 2006).

In contrast, in the present study, the structural complexity of individual plants (number and patterns of ramifications) had no or only a slight influence on the egg distribution of the tansy leaf beetle and none on the probability of parasitism by $O$. galerucivorus. The female beetles were more attracted by simple than complex plant stems, possibly because they prefer tall grass stems to smaller herbs with a greater complexity for oviposition. Therefore, another plant architectural trait, plant height, had a strong positive influence on herbivore beetle oviposition and, being correlated with egg clutch height, a negative influence on the probability of parasitism. Supporting this, a previous study (Obermaier et al., 2006) shows that beetles select the tallest plants within the vegetation for oviposition and oviposited as high as possible on these plants. As the egg parasitoid mainly searches for its host by running up vertical structures (T. Meiners, pers. observ.), ovipositing high up in the vegetation seems to reduce the likelihood of the higher located egg clutches being parasitized. Thus, choosing high oviposition sites on tall plants within the herbaceous vegetation may result in a selective advantage compared to ovipositing on complex structured plants.

Also, at the larger spatial scale it was hypothesized that tall and complex vegetation structure might provide enemy free space for insect herbivores. Several studies record that vegetation height and structural complexity affect herbivore species richness (Stinson \& Brown, 1983), population density (Dennis, 2004), habitat colonization (Coll \& Bottrell, 1994), mate finding (Langellotto \& Denno, 2001) and host plant detection (Anthes et al., 2003). Regarding natural enemies the effect of vegetation structure varies. In a previous study, at two larger spatial scales, both a similar effect of vegetation structure on the occurrence of both the beetle and the parasitoid and no effect on parasitism were recorded (Meiners \& Obermaier, 2004). An investigation of larval predation and egg parasitism in the shield beetle species C. rubiginosa revealed a higher predation risk of larvae on exposed host plants, but no influence on egg parasitism or oviposition site choice of the female beetles (Tschanz et al., 2005). On the other hand a meta-analysis revealed that seven out of nine natural enemy guilds are more abundant in complex habitats (Langellotto \& Denno, 2004).

In the present study, vegetation structure had a highly significant influence both on the egg distribution of the herbivore and on parasitism by $O$. galerucivorus at the microhabitat scale, i.e. close to the oviposition site. While beetle egg clutches were found more often in plots with tall and dense vegetation, their risk of being parasitized was higher in low and open vegetation as both the occurrence and rate of parasitism were negatively correlated with height and density of the surrounding vegetation. The model of egg clutch occurrence related to "vegetation 
structure" was successfully cross-validated at the two study sites. Tall and dense "vegetation structure", combining the parameters stalk number, horizontal cover, and average and maximum vegetation height per plot, seemed to provide enemy free space for the beetle females to hide their eggs from parasitoids. This oviposition pattern is in accordance with optimal oviposition theory, which predicts that females should oviposit at those sites that enhance the performance and survival chances of their offspring (Jaenike, 1978; Thompson, 1988; Thompson \& Pellmyr, 1991; Heisswolf et al., 2005).

In addition, the probability of parasitism was positively correlated with host density (positive density dependence), i.e. depositing too many eggs in dense vegetation may counteract the selective advantage of hiding eggs in dense vegetation. A positive density dependence of parasitism at this scale accords with earlier results on the sensory capabilities of a close congener of the egg parasitoid examined, O. gallerucae, which locates the microhabitat of its host by odours and contact cues (kairomones) in the host's faeces (Meiners \& Hilker, 1997). Similarly, the residence time of O. galerucivorus in plots with high egg clutch densities and their probability of finding host eggs may increase, as a result of more frequent contact with beetle faeces.

Combining the structure at both spatial scales, i.e., plant architecture and vegetation structure, did not improve the model compared to using vegetation structure alone. Since egg clutch height, and therefore plant height, and vegetation structure were significantly positively correlated we suggest that the height and the density of the surrounding vegetation influence the height of the plants selected for oviposition and are the main determinants of parasitism of the beetle eggs.

Results of this study accord with a recent investigation of the movement patterns of the parasitoid in vegetation of different structural complexity (vegetation height, density and connectivity) (Randlkofer et al., in prep.). This behavioural study explicitly shows that the movement pattern of the parasitoid depends on vegetation structural complexity.

The present study indicates that the oviposition plant and an area with a radius of $10 \mathrm{~cm}$ around it is the scale most important for the host-parasitoid interaction. At this small spatial scale the herbivore and its parasitoid differed in their patterns of oviposition, possibly because of the reduced host finding success of the parasitoid in tall or structurally complex plants and vegetation. Height and structural complexity of individual plants and of the herbaceous vegetation seem not only to influence oviposition patterns, but actually to mediate the host-parasitoid interaction by providing the herbivore with enemy free space. That is, apart from the host plant, the structure and complexity of the environment can have important implications for multitrophic level interactions.

ACKNOWLEDGEMENTS. We are grateful to B. Schröder for statistical advice. E. Obermaier thanks the bureau of women's affairs of the University of Würzburg and the BMBF (MOSAIC-project, code 01LN0007) for financial support. The authors thank the government of Lower Franconia for permission to work in the nature reserve.

\section{REFERENCES}

Andow D.A. \& Prokrym D.R. 1990: Plant structural complexity and host-finding by a parasitoid. Oecologia 82: 162-165.

anthes N., Fartmann T., Hermann G. \& Kaule G. 2003: Combining larval habitat quality and metapopulation structure the key for successful management of pre-alpine Euphydryas aurinia colonies. J. Insect Conserv. 7: 175-185.

BACH C.E. 1984: Plant spatial pattern and herbivore population dynamics: plant factors affecting the movement patterns of a tropical cucurbit specialist (Acalymma innubum). Ecology 65: $175-190$.

Berdegué M., Trumble J.T., Hare J.D. \& Redak R.A. 1996: Is it enemy-free space? The evidence for terrestrial insects and freshwater arthropods. Ecol. Entomol. 21: 203-217.

Bernays E.A. \& Chapman R.F. 1994: Host-Plant Selection by Phytophagous Insects. Chapman and Hall, New York, 312 pp.

BonN A. \& SCHRÖDER B. 2001: Habitat models and their transfer for single and multiple species groups: a case study of carabids in an alluvial forest. Ecography 24: 483-496.

CASAS J. \& DJemai I. 2002: Canopy architecture and multitrophic interactions. In Tscharntke T. \& Hawkins B.A. (eds): Multitrophic Level Interactions. Cambridge University Press, Cambridge, pp. 174-196.

Coll M. \& Bottrell D.G. 1994: Effects of non host plants on an insect herbivore in diverse habitats. Ecology 75: 723-731.

Crist T.O., Guertin D.S., Wiens J.A. \& Milne B.T. 1992: Animal movement in heterogeneous landscapes: an experiment with Eleodes beetles in shortgrass prairie. Funct. Ecol. 6: $536-544$.

CRONIN J.T. 2003: Matrix heterogeneity and host-parasitoid interactions in space. Ecology 84: 1506-1516.

DenNIS R.L.H. 2004: Just how important are structural elements as habitat components? Indications from a declining lycaenid butterfly with priority conservation status. J. Insect Conserv. 8: $37-45$.

FinKe D.L. \& DenNo R.F. 2002: Intraguild predation diminished in complex-structured vegetation: Implications for prey suppression. Ecology 83: 643-652.

Fleishman E., Mac Nally R. \& Fay J.P. 2003: Validation tests of predictive models of butterfly occurrence based on environmental variables. Conserv. Biol. 17: 806-817.

Gingras D., Dutilleul P. \& Boivin G. 2002: Modeling the impact of plant structure on host-finding behavior of parasitoids. Oecologia 130: 396-402.

Gingras D., Dutilleul P. \& Boivin G. 2003: Effect of plant structure on host finding capacity of lepidopterous pests of crucifers by two Trichogramma parasitoids. Biol. Control 27: 25-31.

Gratton C. \& Welter S.C. 1999: Does "enemy-free space" exist? Experimental host shifts of an herbivorous fly. Ecology 80: $773-785$.

Guisan A. \& Zimmermann N.E. 2000: Predictive habitat distribution models in ecology. Ecol. Model. 135: 147-186.

Heisswolf A., Obermaier E. \& PoethKe H.J. 2005: Selection of large host plants for oviposition by a monophagous leaf beetle: nutritional quality or enemy-free space? Ecol. Entomol. 30: 299-306.

Hopkins G.W. \& Dixon A.F.G. 1997: Enemy-free space and the feeding niche of an aphid. Ecol. Entomol. 22: 271-274.

Hosmer D.W. \& Lemeshow S. 2000: Applied Logistic Regression. Wiley, New York, 373 pp. 
JAENIKE J. 1978: On optimal oviposition behaviour in phytophagous insects. Theor. Popul. Biol. 14: 350-356.

Jefrries M.J. \& Lawton J.H. 1984: Enemy free space and the structure of ecological communities. Biol. J. Linn. Soc. 23 : 269-286.

Jongman R.H.G., Braak C.J.F. \& Tongeren O.F.R. 1995: Data Analysis in Community and Landscape Ecology. Cambridge University Press, Cambridge, $300 \mathrm{pp}$.

Kaitaniemi P., Vehviläinen H. \& RuohomäKi K. 2004: Movement and disappearance of mountain birch defoliators are influenced by the interactive effects of plant architecture and induced resistance. Ecol. Entomol. 29: 437-446.

Kemp W.P. \& Simmons G.A. 1978: The influence of stand factors on parasitism of spruce budworm eggs by Trichogramma minutum. Envir. Entomol. 7: 685-688.

Langellotto G.A. \& Denno R.F. 2001: Benefits of dispersal in patchy environments: mate location by males of a wingdimorphic insect. Ecology 82: 1870-1878.

Langellotto G.A. \& Denno R.F. 2004: Responses of invertebrate natural enemies to complex-structured habitats: a metaanalytical synthesis. Oecologia 139: 1-10.

LüHMANN M. 1939: Beiträge zur Biologie der Chrysomeliden. 4. Beobachtungen an Galeruca tanaceti Lin. Entomol. Blätt. 35: 91-95.

LUKIANCHUK J.L. \& SMith S.M. 1997: Influence of plant structural complexity on the foraging success of Trichogramma minutum Riley: A comparison of search on artificial and foliage models. Entomol. Exp. Appl. 84: 221-228.

Manel S., Williams H.C. \& Ormerod S.J. 2001: Evaluating presence-absence models in ecology: the need to account for prevalence. J. Appl. Ecol. 38: 921-931.

MeINers T. \& HiLKer M. 1997: Host location in Oomyzus gallerucae (Hymenoptera: Eulophidae), an egg parasitoid of the elm leaf beetle Xanthogaleruca luteola (Coleoptera: Chrysomelidae). Oecologia 112: 87-93.

Meiners T. \& Obermaier E. 2004: Hide and seek on two spatial scales - vegetation structure effects herbivore oviposition and egg parasitism. Basic Appl. Ecol. 5: 87-94.

Meiners T., Köpf A., Stein C. \& Hilker M. 1997: Chemical signals mediating interactions between Galeruca tanaceti L. (Coleoptera, Chrysomelidae) and its egg parasitoid Oomyzus galerucivorus (Hedqvist) (Hymenoptera, Eulophidae). $J$. Insect Behav. 10: 523-539.

Meiners T., Randlkofer B. \& Obermaier E. 2006: Oviposition at low temperatures - late season negatively affects the leaf beetle Galeruca tanaceti (Coleoptera: Galerucinae) but not its specialised egg parasitoid Oomyzus galerucivorus (Hymenoptera: Eulophidae). Eur. J. Entomol. 103: 765-770.

NAGELKeRKe N.J.D. 1991: A note on the general definition of the coefficient of determination. Biometrika 78: 691-692.

OBermaier E. \& ZwöLfer H. 1999: Plant quality or quantity? Host exploitation strategies in three Chrysomelidae species associated with Asteraceae host plants. Entomol. Exp. Appl. 92: $165-177$.

Obermaier E., Heisswolf A., Randlkofer B. \& Meiners T. 2006: Enemies in low places - insects avoid winter mortality and egg parasitism by modulating oviposition height. Bull. Entomol. Res. 96: 1-7.

PrevetT P.F. 1953: Notes on the feeding habits and life-history of Galeruca tanaceti L. (Col., Chrysomelidae). Entomol. Mon. Mag. 89: 292-293.

Price P.W., Bouton C.E., Gross P., McPheron B.A., Thompson J.N. \& WeIs A.E. 1980: Interactions among three trophic levels: influence of plants on interactions between insect herbivores and natural enemies. Annu. Rev. Ecol. Syst. 11: 41-65.

Quicke D.L.J. 1997: Parasitic Wasps. Chapman and Hall, London, $470 \mathrm{pp}$.

Raghu S., Drew R.A.I. \& Clarke A.R. 2004: Influence of host plant structure and microclimate on the abundance and behavior of a tephritid fly. J. Insect Behav. 17: 179-190.

RiıhimäKi J., Vehviläinen H., Kaitaniemi P. \& Koricheva J. 2006: Host tree architecture mediates the effect of predators on herbivore survival. Ecol. Entomol. 31: 227-235.

RUDGERS J.A. \& WhitNEY K.D. 2006: Interactions between insect herbivores and a plant architectural dimorphism. $J$. Ecol. 94: 1249-1260.

SCHRÖDER B. \& REINEKING B. 2004: Validierung von Habitatmodellen. In Dormann C.F., Blaschke T., Lausch A., Schröder B. \& Söndgerath D. (eds): Habitatmodelle - Methodik, Anwendung, Nutzen. UFZ-Berichte Vol. 9, Leipzig, pp. 47-56.

SinACORI A. \& Mineo G. 1993: Nota preliminare su Galeruca spp. (Coleoptera: Chrysomelidae) delle Madonie. Frust. Entomol. 16: 97-110.

SoKal R.R. \& RohlF F.J. 1995: Biometry. Freeman, New York, $887 \mathrm{pp}$.

Stinson C.S.A. \& Brown V.K. 1983: Seasonal changes in the architecture of natural plant communities and its relevance to insect herbivores. Oecologia 56: 67-69.

SuNDERMEIER A. 1999: Zur Vegetationsdichte der Xerothermrasen nordwestlich von Halle/Saale. Cramer, Berlin, 194 pp.

THOMPson J.N. 1988: Evolutionary ecology of the relationship between oviposition preference and performance of offspring in phytophagous insects. Entomol. Exp. Appl. 47: 3-14.

Thompson J.N. \& Pellmyr O. 1991: Evolution of oviposition behavior and host preference in Lepidoptera. Annu. Rev. Entomol. 36: 65-89.

Tschanz B., Schmid E. \& Bacher S. 2005: Host plant exposure determines larval vulnerability - do prey females know? Funct. Ecol. 19: 391-395.

Zweig M.H. \& CAMPBell G. 1993: Receiver-operating characteristic (ROC) plots: a fundamental tool in clinical medicine. Clin. Chem. 39: 561-577.

Received August 22, 2007; revised and accepted November 12, 2007 